XXVI Congresso de Iníciaçăo cientifica Unicamp
17 a 19 de outubro Campinas | Brasil
8

\title{
A fotografia como recurso terapêutico no contexto hospitalar
}

\section{Claudia Regina Oga*, Marcelo Simões Mendes}

\begin{abstract}
Resumo
A humanização em saúde, como um dos parâmetros para o atendimento em saúde no Brasil, foi consolidada com o intuito de oferecer um suporte na busca por uma nova cultura de atendimento baseada na melhoria dos relacionamentos entre os atores envolvidos na área. Entretanto, constatou-se que existe ainda um longo percurso a ser percorrido pelas instituições para que elas ofereçam um atendimento que respeite a singularidade dos sujeitos. A fotografia é uma expressão artística que tem sido utilizada no contexto hospitalar como um recurso terapêutico para promover reflexões que remetem à necessidade do cuidado humanizado. Este estudo teve como objetivo investigar o potencial terapêutico do uso da fotografia na melhoria da qualidade de vida das pessoas que estão passando por tratamento em instituições de saúde. Adotou-se uma metodologia qualitativa a partir do enfoque do estudo de caso. Foi realizada uma entrevista semidirigida com uma educadora de uma instituição que faz intervenções fotográficas em hospitais. Para complementar os dados obtidos, realizou-se uma pesquisa documental no acervo desta instituição. A análise do conteúdo foi desenvolvida segundo a técnica de categorização temática. Humanização, cuidado em saúde, promoção da saúde e a relação arte e saúde foram os eixos da pesquisa, e identificaram-se alguns temas que interferem na qualidade do atendimento: subjetividade, autonomia, formação profissional e comunicação. A pesquisa revelou que a fotografia produziu reflexões sobre o cuidar que repercutiram na dinâmica das relações entre profissionais, pacientes e acompanhantes. Assim, considerou-se que a fotografia interferiu no processo saúde-doença, tornando-o mais humanizado, o que contribui para o desenvolvimento do sujeito, com impactos na sua qualidade de vida.
\end{abstract}

\section{Palavras-chave:}

Psicologia, Humanização hospitalar, Fotografia.

\section{Introdução}

A humanização no Brasil foi consolidada a partir da criação do Programa Nacional de Humanização da Assistência Hospitalar (PNHAH) em 2000 com o intuito de oferecer um suporte na busca por uma nova cultura de atendimento (MELLO, 2008), pois o hospital, em sua constituição organizacional, impõe o isolamento, a despersonalização e a submissão disciplinar do corpo e da subjetividade dos pacientes a procedimentos e decisões, sobre os quais, muitas vezes, eles não compreendem (DESLANDES, 2004). Este trabalho teve como objetivo investigar o potencial terapêutico da fotografia para pessoas que estão passando por tratamento em instituições de saúde, e identificar e analisar as relações estabelecidas entre este trabalho fotográfico e a qualidade de vida dos pacientes a partir da visão dos educadores de fotografia.

\section{Resultados e Discussão}

A pesquisa segue os princípios da metodologia de pesquisa qualitativa de estudo de caso, e teve como sujeito uma educadora de uma instituição que realiza intervenções fotográficas no contexto hospitalar. Como instrumentos, utilizou-se a pesquisa documental no acervo da instituição e a entrevista semidirigida. A análise do conteúdo foi desenvolvida segundo a técnica de categorização de Bardin (1977). Foram abordados os eixos: humanização, cuidado em saúde, promoção da saúde, relação entre arte e saúde. Como resultados, foi possível identificar alguns temas em comum aos eixos, os quais interferem na qualidade do atendimento: subjetividade, autonomia, formação profissional, comunicação. Na área da saúde, a fotografia apresentou vantagens, como a simplicidade no manuseio e a possibilidade de se visualizar o ponto de vista de outra pessoa, através de um registro produzido diretamente por ela. Por intermédio do jogo criativo da arte e da acessibilidade da fotografia, muitos profissionais conseguiram estabelecer novos modos de comunicação no contexto hospitalar.

\section{Conclusões}

Os trabalhos realizados com fotografia em hospitais mostraram que esta ferramenta interferiu positivamente no processo de tratamento dos pacientes, com o uso da criatividade, a ressignificação da instituição de saúde, etc. A pesquisa revelou que a fotografia produziu reflexões sobre o cuidar que repercutiram na dinâmica das relações entre profissionais, pacientes e acompanhantes. Assim, constatou-se que a fotografia pode ser um instrumento terapêutico no contexto hospitalar capaz de interferir no processo de promoção da saúde, tornando-o mais humanizado e interativo, o que contribui para o desenvolvimento do sujeito, com impactos no seu bem-estar e na sua qualidade de vida.

\section{Agradecimentos}

Esta pesquisa teve o apoio da Vice-Reitoria de PósGraduação e Pesquisa da Universidade Paulista - Unip.

BARDIN, Laurence. Análise de Conteúdo. Lisboa: Edições 70, 1977.

DESLANDES, Suely F. Análise do discurso oficial sobre a humanização da assistência hospitalar. Ciênc. saúde coletiva, Rio de Janeiro, v. 9, n. 1, p. 7-14, 2004. Disponível

<http://www.scielo.br/scielo.php?script=sci_arttext\&pid=S1413-

$81232004000100002 \& \operatorname{lng}=$ en\&nrm=iso>. Acesso em: 24 jul. 2017.

MELLO, Inaiá Monteiro. Humanização da Assistência Hospitalar no Brasil: conhecimentos básicos para estudantes e profissionais. Produção Técnico e Científica do Núcleo Técnico de Humanização da FMUSPHC (Faculdade de Medicina da USP/Hospital das Clínicas.), São Paulo, 2008. Disponível em:<http://hc.fm.usp.br/humaniza/publicacoes.html> . Acesso em: 23 ago. 2016. 